\title{
Influence of Freeze-Dried Diet on Oral Hygiene Indicators in Strict Isolation Condition of an Analog Space Mission
}

\author{
Barbara Janina Gronwald ${ }^{1, *}$, Karina Kijak ${ }^{2}$, Karolina Jezierska ${ }^{3}$, Helena Anna Gronwald ${ }^{4}$ (D), Kamil Kosko ${ }^{5}$, \\ Mikołaj Matuszczak ${ }^{2}$, Hanna Barbara Bielawska-Victorini ${ }^{6}$, Wojciech Podraza ${ }^{3} \mathbb{D}$, Leszek Orzechowski ${ }^{7}$ \\ and Danuta Lietz-Kijak ${ }^{4}$
}

Citation: Gronwald, B.J.; Kijak, K.; Jezierska, K.; Gronwald, H.A.; Kosko,

K.; Matuszczak, M.;

Bielawska-Victorini, H.B.; Podraza, W.; Orzechowski, L.; Lietz-Kijak, D Influence of Freeze-Dried Diet on Oral Hygiene Indicators in Strict Isolation Condition of an Analog Space Mission. Int. J. Environ. Res. Public Health 2022, 19, 1367. https:/ / doi.org/10.3390/ijerph19031367

Academic Editor: Iole Vozza

Received: 15 December 2021

Accepted: 23 January 2022

Published: 26 January 2022

Publisher's Note: MDPI stays neutral with regard to jurisdictional claims in published maps and institutional affiliations.

Copyright: (C) 2022 by the authors. Licensee MDPI, Basel, Switzerland. This article is an open access article distributed under the terms and conditions of the Creative Commons Attribution (CC BY) license (https:// creativecommons.org/licenses/by/ $4.0 /)$
1 Doctoral Study at the Department of Propaedeutics, Physical Diagnostics and Dental Physiotherapy, Pomeranian Medical University in Szczecin, 71-210 Szczecin, Poland

2 Scientific Student Group STO-MATER-FIZ at the Department of Propaedeutics, Physical Diagnostics and Dental Physiotherapy, Pomeranian Medical University in Szczecin, 70-111 Szczecin, Poland; karo0326@gmail.com (K.K.); mikolaj.matuszczak@gmail.com (M.M.)

3 Department of Medical Physics, Pomeranian Medical University in Szczecin, 71-073 Szczecin, Poland; karolina.jezierska@pum.edu.pl (K.J.); wojciech.podraza@pum.edu.pl (W.P.)

4 Department of Propaedeutics, Physical Diagnostics and Dental Physiotherapy, Pomeranian Medical University in Szczecin, 70-111 Szczecin, Poland; helenagronwald@gmail.com (H.A.G.); danuta.lietzkijak@gmail.com (D.L.-K.)

5 Individual Dental Practice Kamil Kosko, 62-510 Konin, Poland; kamil.kosko@gmail.com

6 Department of Orthodontics, Pomeranian Medical University in Szczecin, 70-111 Szczecin, Poland; hania.bielawska@wp.pl

7 LunAres Research Station, 64-930 Piła, Poland; orzechleszek@gmail.com

* Correspondence: barbara.gronwald@pum.edu.pl; Tel.:+48-512377448

\begin{abstract}
Analog space missions were created to study the human factor in extraordinary conditions that would occur in future space habitats. Isolation has been shown to cause stress and disrupt individuals' daily routine, which can also affect their oral hygiene and lead to an increased risk of dental caries and gingivitis. The astronauts' specific freeze-dried diet is associated with "lazy" chewing, potential dehydration and vitamin A deficiency, which may adversely affect their saliva. The aim of this study is to investigate the influence of the freeze-dried diet on selected oral hygiene indicators in analog astronauts (AA) enduring strict isolation conditions during six consecutive analog space missions at the LunAres Research Station. During the experiment the oral hygiene and gingival inflammation status measurements were conducted on the group of AAs at the beginning and at the end of each mission. Measurements included four oral hygiene indicators: API, sOHI, PI by Silness and Loe and GBI by Ainamo and Bay. Each AA's individual scores were noted and analyzed. Statistically significant reduction in the amount of plaque and intensity of gingival bleeding was observed over the course of the study, which could indicate positive results of applied oral hygiene procedures despite unfavorable dietary and stressful isolation conditions.
\end{abstract}

Keywords: analog space mission; freeze-dried diet; isolation; oral hygiene; oral health

\section{Introduction}

Research on various aspects of life in space, conducted all over the world, is gaining momentum as the vision of conducting extra-terrestrial missions slowly becomes a reality. What a few decades ago seemed like a fantasy, is taken today with utmost seriousness, because we realize how much preparation and research still needs to be carried out. The main research center in the field of space exploration is the US National Aeronautics and Space Administration (NASA). However, the centers, particularly focusing on the human factor and its possible adaptation to the conditions of life in space, are primarily analog space bases where analog astronauts can face the difficulties and challenges of taking part in a mission in a controlled environment. Some of such research even provides insides into 
important team- and individual-level variables during stressful space analog events, while considering factors related to human psychology, which allows for a better understanding of the factors affecting astronaut teams in these contexts [1]. Other analog missions conducted in remote areas focus on preparing the analog astronauts and developing necessary laboratory analytical methods and techniques comparable with those that would likely be used in the future on Mars (AMADEE-18 mission; Dhofar area, Oman) [2].

One of only six such centers in the world and the only one in Europe is the LunAres Research Station in Piła (Poland), established in 2017 (Figure 1).

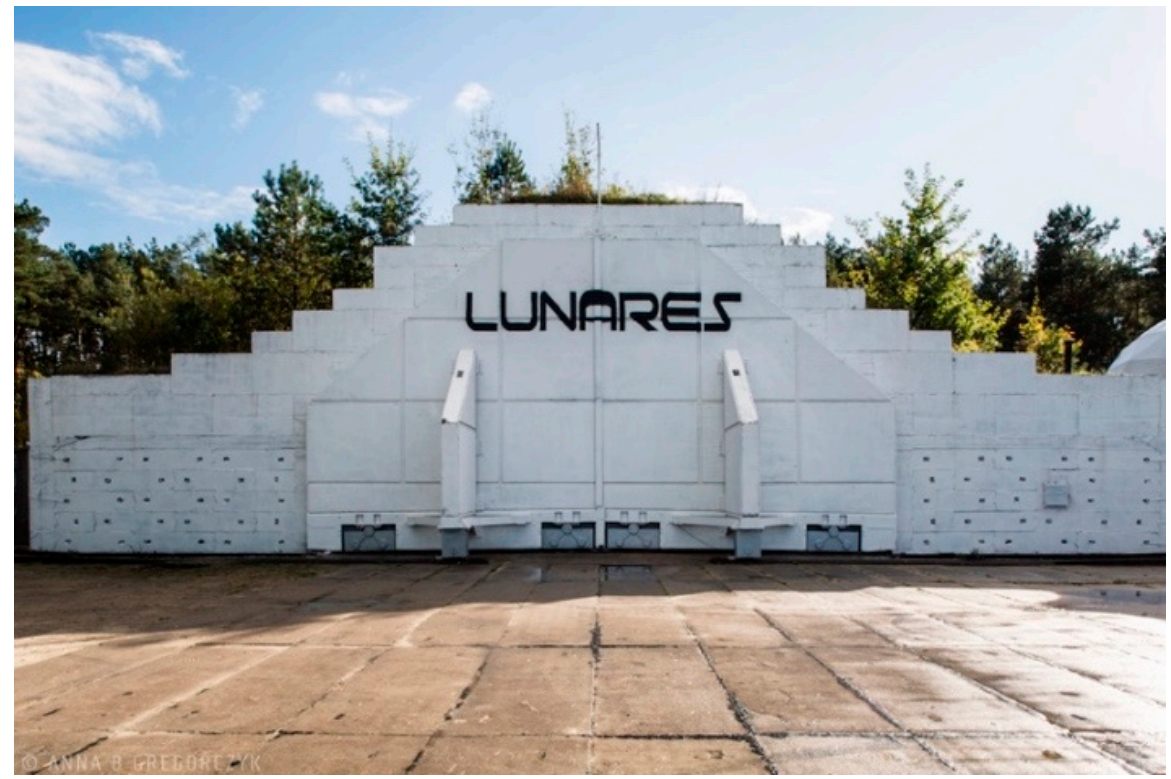

Figure 1. LunAres Research Station—Analog space base (Piła, Poland).

This analog space base is housed in an extended and specially adapted airplane hangar, used mainly for research of a interdisciplinary nature, conducted during manned missions with the participation of scientists and collaborators from around the world (Figure 2).

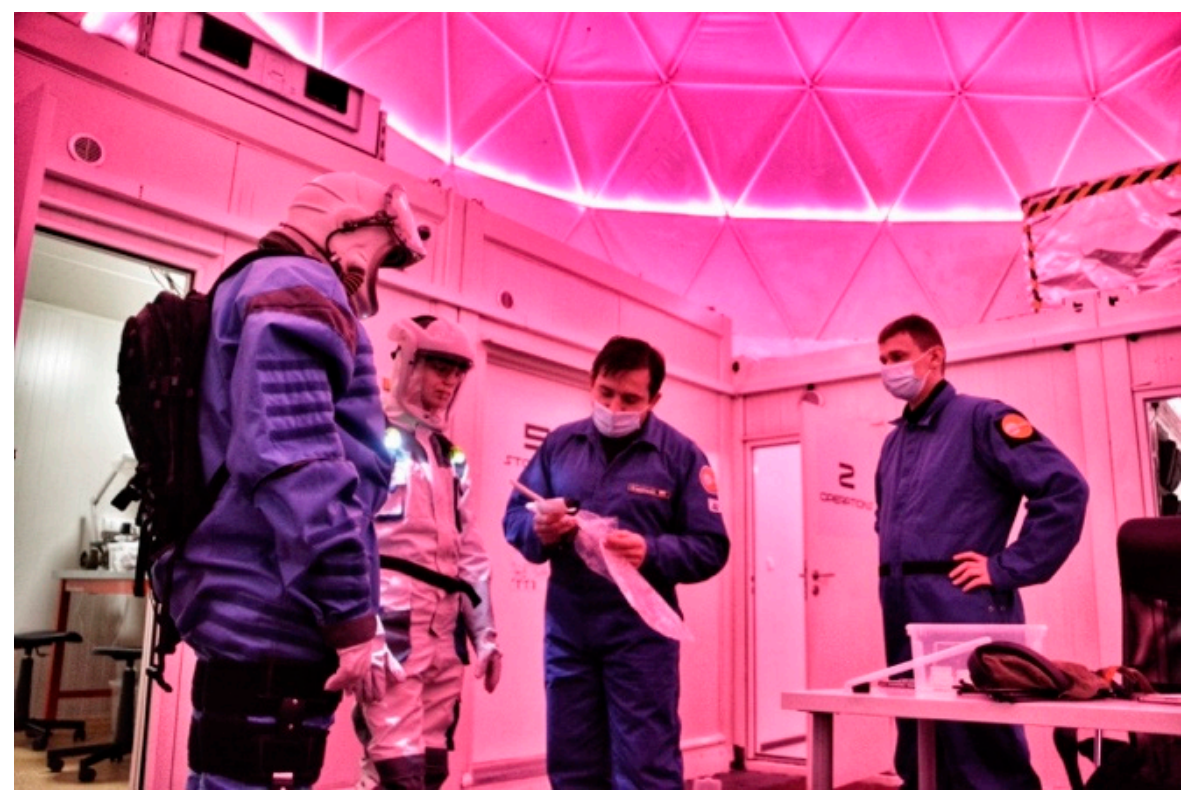

Figure 2. Analog astronauts during one of the analog space missions of Pandemic Isolation Campaign (2021). 
The main goal of LunAres is to create a research platform to support scientific and technological development in manned space explorations, creating a unique research opportunity to conduct interdisciplinary experiments. The broad range of specialists are involved in the study from various fields, including extreme medicine, psychology, biotechnology, robotics and engineering, sustainability, extreme plant cultivation, sociology, and architecture. The possible observation and control of the indoor environment, as well as telemetry of the crew's physical and psychological states allows us to observe the impact of simulated Martian and Lunar conditions on people staying periodically in strict isolation from the outside world, as well as to prepare procedures and solve problems that may arise during real space expeditions. This makes the center an indispensable link in preceding space research and cosmic expeditions-as demonstrated by Dr. Sian Proctor, crew member of Inspiration4, the first civilian flight into space (September 2021), who also trained at the LunAres Research Station.

The LunAres base is located at the post-military airport in Poland. The facility provides full isolation from the external environment including 250 square meters of EVA area (extravehicular activity area), allowing for 2 week missions for a 6-person crew. The infrastructure of the station provides constant monitoring of health and behavior of the crew (Figure 3).

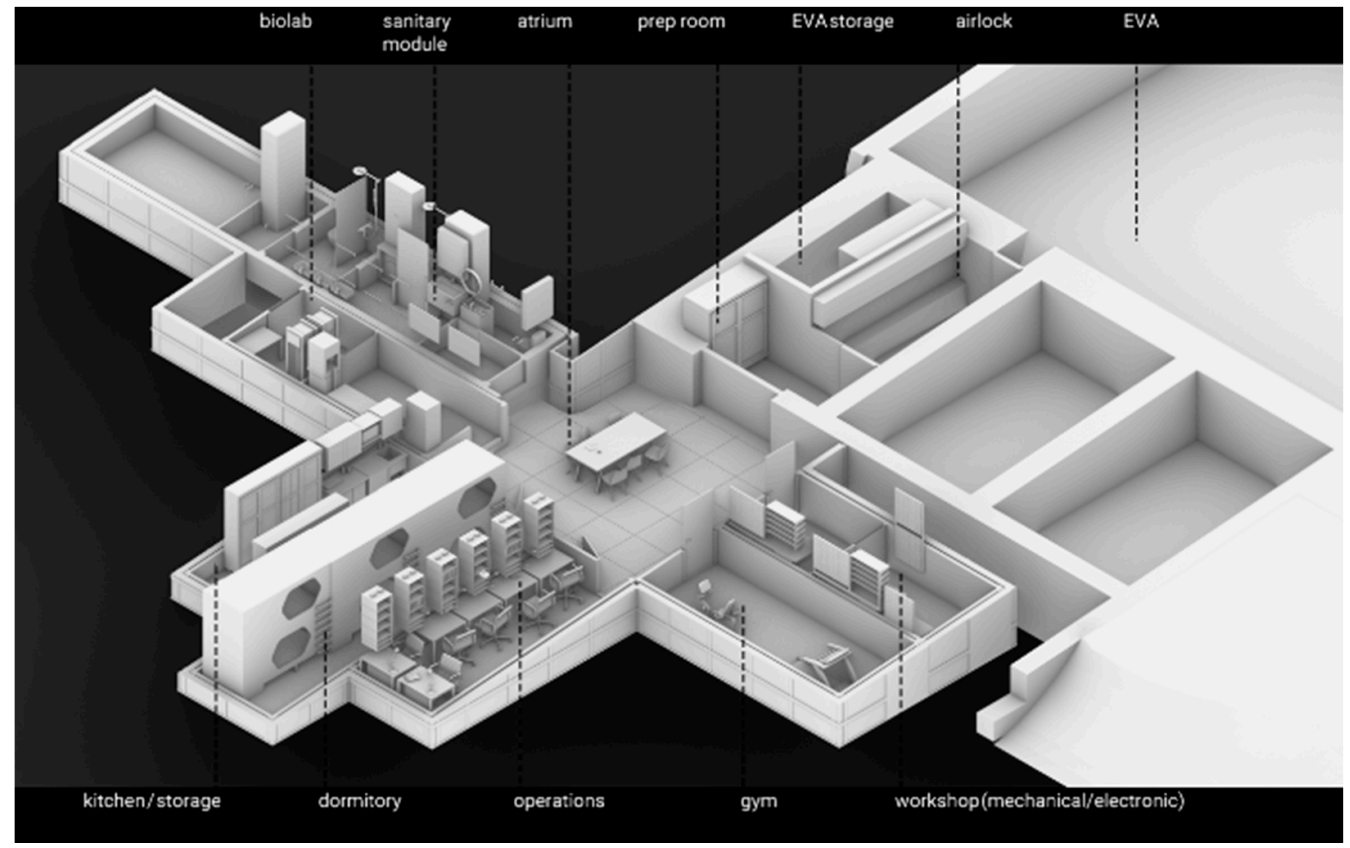

Figure 3. The infrastructure of the analogue space station in Piła.

Research on the influence of isolation and long-term stress on the physiology of the human body is extremely difficult due to the numerous variables that can determine the parameters measured. In order to eliminate the influence of accidental factors, the research team of the Department of Propaedeutics, Physical Diagnostics and Dental Physiotherapy of the Pomeranian Medical University in Szczecin has cooperated with LunAres Research Station since 2018. The conducted research provides an opportunity to examine the impact of various factors, e.g., freeze-dried diet, stress and isolation on the stomatognathic system. During the missions of the Pandemic Isolation Campaign, the emphasis was put on a freeze-dried diet and isolation.

It is important to consider some aspects of astronaut's life-especially periods of strict isolation and high levels of stress. Scientists have demonstrated that isolation can induce stress and affect a person's everyday routine. Any potential neglect of oral hygiene routine can occur, and, due to oral biofilm formation and development, impact a person's health by increasing the risk of dental caries, periodontal disease (gingivitis or periodontitis) and 
peri-implantitis [3]. The oral cavity appears as an open ecosystem, with a dynamic balance between the entrance of microorganisms, colonization modalities and host defenses aimed to their removal; to avoid elimination, bacteria need to adhere to either hard dental surfaces or epithelial surfaces [3]. Potential plaque accumulations on tooth surface or gums (due to lack of proper oral hygiene) are ideal conditions for bacteria growth. Thanks to the wet and warm environment of the oral cavity with constant nourishment and access, bacteria in the oral plaque begin to develop into biofilms and maturate. Due to the maturation process, the biofilm colony produces more and more toxic by-products that stimulate the host's immune responses. Studies closely examining inflammatory process occurring in affected periodontal tissues suggests the existence of an inflammatory response in these tissues by increased mRNA level of prostaglandin-endoperoxide synthase (PTGS2), multiple cytokines and chemokines, which arise mainly from resident fibroblasts, keratinocytes and endothelial cells [4]. As a result of the mentioned risks, all mission participants had to adhere strictly to the detailed daily schedule.

The freeze-drying process consists of drying food products after freezing them with the use of reduced pressure, resulting in the removal of $70 \%$ to $96 \%$ of the water. This procedure allows us to inhibit the microorganism's growth and slow down enzymatic processes to very high degree [5,6]. This method ensures preservation of the product nutritional value, and because the food is dried, it is lighter and has a longer shelf life. These properties make a freeze-dried or lyophilized diet especially recommended for astronauts (but also climbers, sailors and soldiers) and in the 1960s, it was used for the first time on a larger scale for astronauts of the Skylab mission [7-9].

However, even most sophisticated food preservation methods are not ideal and during the free-drying process also occurs some loss of active ingredients, such as the phytochemical components of the products. It was proven that some tropical fruits can significantly lose their vitamin $C$ content due to freeze-drying [10]. These deficits are impacted by the lyophilization process itself, e.g., the freeze-drying of the sea buckthorn berries at $20{ }^{\circ} \mathrm{C}$ shelf temperature and $30 \mathrm{~m}$ Torr vacuum pressure caused a 20\% loss in vitamin $\mathrm{C}$ and in total carotenoids and a $35 \%$ loss in vitamin E, but only a $4 \%$ loss in total phenolics [11]. Also the type of bio-compound we try to preserve plays a big role in the potential loss of active ingredients of preserved food. Studies concluded that retention of vitamin C and phenolic content is best achieved by the process of freeze-drying, but in terms of the preservation of $\beta$-carotene, lycopene, vitamin E, unsaturated oils, and other lipid-based oxidizable bio-compounds, the lyophilization process could damage the quality of lipidbased bio-compounds, due to autocatalytic oxidative reactions accelerating at very low water activities, which are achieved during the freeze-drying procedure [12]. Nevertheless, when compared to other food preservation techniques, freeze-drying is usually a superior technology [13-15].

On the other hand, proper nutrition influences the course of developmental processes of individual elements of the masticatory organs and is responsible for maintaining the health of the tissues of the oral cavity $[16,17]$. For instance, a specific aspect of too-high food fragmentation in astronauts' diet is associated with "lazy" chewing, potential dehydration or vitamin A deficiency, which may result in a reduction in the amount of saliva produced or its increased density [18]. In addition, dried food differs in consistency after rehydration from its regular state. Studies demonstrate that dried fruits after ingestion become "sticky" in the oral cavity and adhere to tooth surface, which can lead to plaque accumulation, local gingival inflammation or caries $[19,20]$. This only underscores the importance and need of research in this field.

The aim of the research was to investigate the influence of a freeze-dried diet on selected oral hygiene and gingival inflammation indicators in conditions of strict isolation during consecutive analog space missions in 2021 as part of the Pandemic Isolation Campaign at the LunAres Research Station. 


\section{Materials and Methods}

Oral hygiene and gingival status studies were conducted in a group of 31 analog astronauts (AA) who consumed only freeze-dried products for 14 days and endured the rigorous conditions of isolation on the limited space of the analog habitat at the LunAres Research Station during 6 consecutive analog space missions in 2021 as part of the Pandemic Isolation Campaign.

$5 \mathrm{AA}($ mission 1$)+6 \mathrm{AA}($ mission 2$)+6 \mathrm{AA}($ mission 3$)+5 \mathrm{AA}($ mission 4$)+4 \mathrm{AA}($ mission 5$)+5 \mathrm{AA}($ mission 6$)=31 \mathrm{AA}$

AAs participating in the study came from 15 different countries, thus, the study group was ethnically heterogenic, varied in age (21-60 years of age), dietary and hygienic habits as well as oral cavity status. The above-mentioned initial measurements (before the application of study conditions: freeze-dried diet, isolation, oral hygiene regimen) were considered the control, and final measurements (after the study condition impact) were considered the test group.

To ensure exclusion of numerous environmental variables, rigorous isolation conditions were incorporated and tested in all analog astronaut missions at the LunAres Research Station, including:

- $\quad$ Complete lack of access to sunlight (the time of day was simulated with artificial lighting);

- $\quad$ Strict prohibition to leave the facility for the entire duration of the mission (14 days);

- $\quad$ Limited contact with the outside world barring absolute emergency (only scheduled contact with mission ground control);

- $\quad$ Limited amount of water for personal hygiene;

- Limited amount of space and no privacy;

- $\quad$ Obligatory diet composed of freeze-dried food only.

All participants were subjected to conditions and strict adherence to the rules was mandatory. During the study cumulatively, subjects were exposed to conditions of 434 persons/days.

$$
31 \text { AA } \times 14 \text { days }=434 \text { person } / \text { days }
$$

The freeze-dried diet, obligatory for all AA, included 5 meals a day:

1. Breakfast at 8:00;

2. 2nd breakfast at 11:00;

3. Lunch at 13:00;

4. Dessert/snack at 16:00;

5. Dinner at 19:30.

Each of the participants could choose their meals from a provided list (Appendix A) beforehand and during the analog mission had to adhere to predetermined choices and meal preparation instructions, especially in terms of water additions. Possible snacking aside from the schedule was allowed unless it could impact the eating routine. All analog astronauts also need to drink minimum 2 liters of bottled water a day, except for water added to prepare meals which on average was approximately $1000 \mathrm{~mL}$ per day (depending on the meal selected, it ranged between 550-1900 mL per day per analog astronaut). In case of warm beverages, the amount was not restricted but could not impact water consumption. Only herbal (mint, rosehip, and chamomile) or fruit (raspberry) infusion was allowed-no coffee nor tea (neither green or black) — to not disturb the regular sleeping patterns of participants with caffeine or theine.

Measurements were taken at the beginning and at the end of each mission so as to not to interfere with the strict isolation conditions imposed during analog immersion (Figure 4).

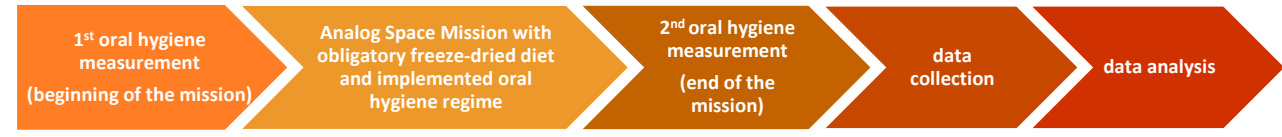

Figure 4. Methodology of the conducted research—single mission. 
The control group of the study consisted of the initial measurement of the subjects, and the test group comprised of the final measurements. In the study, 31 AA (18 women, 13 men) from 15 countries took part, whose ages varied from 21 to 60 years of age (Table 1).

Table 1. Patient and dental material information at the beginning of study.

\begin{tabular}{cccc}
\hline \multirow{2}{*}{ Patient data } & & Medium & Range \\
& Age & 31 & $21-60$ \\
\hline & DMFT & 7.516 & $0-17$ \\
Dental data & API & $33.73 \%$ & $3.30-77.70 \%$ \\
& sOHI & 0.34 & $0-1.16$ \\
& PI & 0.29 & $0-0.83$ \\
\hline
\end{tabular}

Each of the analog astronauts received the same set of dental products for oral hygiene and was trained in various techniques for effective plaque removal according to the iTOP concept. Every set consisted of the Curaprox ultra-soft 5460 manual toothbrush or the Curaprox smart manual toothbrush-depending on the participants' oral cavity size-the Curaprox single 1006 manual single-tufted toothbrush, 2 Curaprox Enzycal 950 toothpastes $(15 \mathrm{~mL}), 2$ sets of Curaprox interdental brushes in 5 different sizes and 2 small packs of Curaprox waxed dental floss (all mentioned products were produced by CURADEN, Switzerland).

iTOP (individually trained oral prophylaxis) is an original concept of individual training in the field of oral prophylaxis and hygiene, which combines theoretical knowledge and practical training in both manual and motivational skills, developed by the company, Curaden. It enables the implementation of the acquired knowledge in everyday dental routine in order to help patients maintain healthy teeth and periodontium for as long as possible. The research team decided to implement iTOP principals into a oral hygiene regimen to ensure proper use of the provided dental products.

The oral hygiene instructions, to which analog astronauts had to strictly adhere for whole duration of the study (14 days), consisted of:

1. Toothbrushing twice a day (at 8:00 and at 22:00) with the provided multi-tufted toothbrush of choice for a duration of at least 2 min with use of the Bass Technique.

2. According to personal needs (determined by research team), the use of the singletufted toothbrush, employing the Bass Technique, is complementary to the brushing routine twice a day.

3. Complete interdental cleaning procedure once a day (at 22:00, after toothbrushing) with the use of interdental brushes or floss (in case of crowding) for a duration of at least $2 \mathrm{~min}$.

Four dental indicators were selected and used in the study: the Proximal Plaque Index (API), simplified Oral Hygiene Index (sOHI), Plaque Index by Silness and Loe (PI) and Gingival Bleeding Index by Ainamo and Bay (GBI), due to their high prevalence in oral hygiene and gingival inflammation research.

- API-Proximal Plaque Index-determines the percentage of interdental spaces with plaque accumulation present in relation to all existing interdental spaces and allows one to assess the hygiene in the interdental spaces.

- $\quad$ sOHI-simplified Oral Hygiene Index — determines the ratio of surfaces covered with dental plaque and calculus on selected teeth; the cumulative plaque and calculus score allows one to evaluate the overall oral hygiene.

- PI-Plaque Index by Silness and Loe-determines the thickness of the plaque along the edge of the teeth gingiva in relation to all the cervical area present and allows one to assess the hygiene in the cervical area.

- $\quad$ GBI-Gingival Bleeding Index by Ainamo and Bay (1975)—determines the percentage of the gingival sulcus with bleeding during probing in relation to all examined gingival 
sulcus present in the area; it enables one to capture gingival inflammation and the early stages of periodontal disease.

The initial oral status of participants showed on average: API scores-33.73\%; sOHI scores-0.34; PI-0.29 and GBI-11.59\% (Table 1).

Each of the analog astronauts (AA) was assigned a code: AA01-AA31, which allowed for the anonymity of the respondents. Initial and final measurements were assigned the same numbers: 1, 2 and, during each of them, the values of all indicators (API, sOHI, PI, and GBI) were determined. All individual results for each of the analog astronauts were recorded and analyzed (Figure 5).

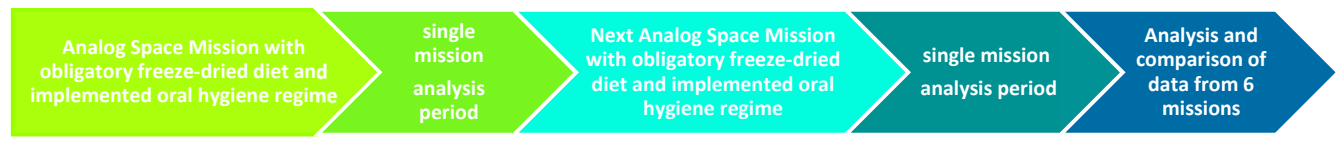

Figure 5. Methodology of data collection and analysis.

The differences in the results between the first and second measurements of all participants of 6 analog missions were compared and the statistical significance was calculated. The statistical analysis of the normal distribution data was performed using the Student's t-test and of the data not following normal distribution was performed using the MannWhitney U test.

\section{Results}

Due to the individuality of the results in the respondents, the relationships were considered separately for each of the indicators, and the trends were analyzed separately for each AA and as a whole for the entire group tested.

\subsection{Approximal Plaque Index}

The API values determine the percentage of interdental spaces with present plaque accumulation in relation to all interdental spaces existing in a persons' oral cavity and allows one to assess the hygiene within the interdental spaces by classifying the test person into one of four categories:

1. $\quad 0-24 \% \rightarrow$ optimal hygiene;

2. $\quad 25-39 \% \rightarrow$ reasonably good hygiene;

3. $40-69 \% \rightarrow$ average hygiene, requiring improvement;

4. $70-100 \% \rightarrow$ insufficient hygiene.

Achieving a lower score or category is equivalent to hygiene improvement and obtaining a higher number or category is equivalent to hygiene deterioration. If the hygiene improves during the experiment (i.e., reaches lower values) or does not deteriorate, this demonstrates that the oral hygiene technique was performed correctly (Figure 6).

On the initial measurement (1), we can observe optimal or good hygiene scores in the 21 out of 31 participants $(67.74 \%)$, which, from a clinical point of view, do not require significant improvement. The remaining 10 analog astronauts (32.26\%) obtained API results classifying them into the categories requiring significant hygiene improvement. Category 3 was assigned to $22.58 \%$ of participants and category 4 to $9.67 \%$. On the final measurement 17 subjects were classified into optimal or good hygiene groups (80.64\%) and only 6 astronauts were in persisting need of hygiene improvement (19.35\%), none of which were in category 4. 


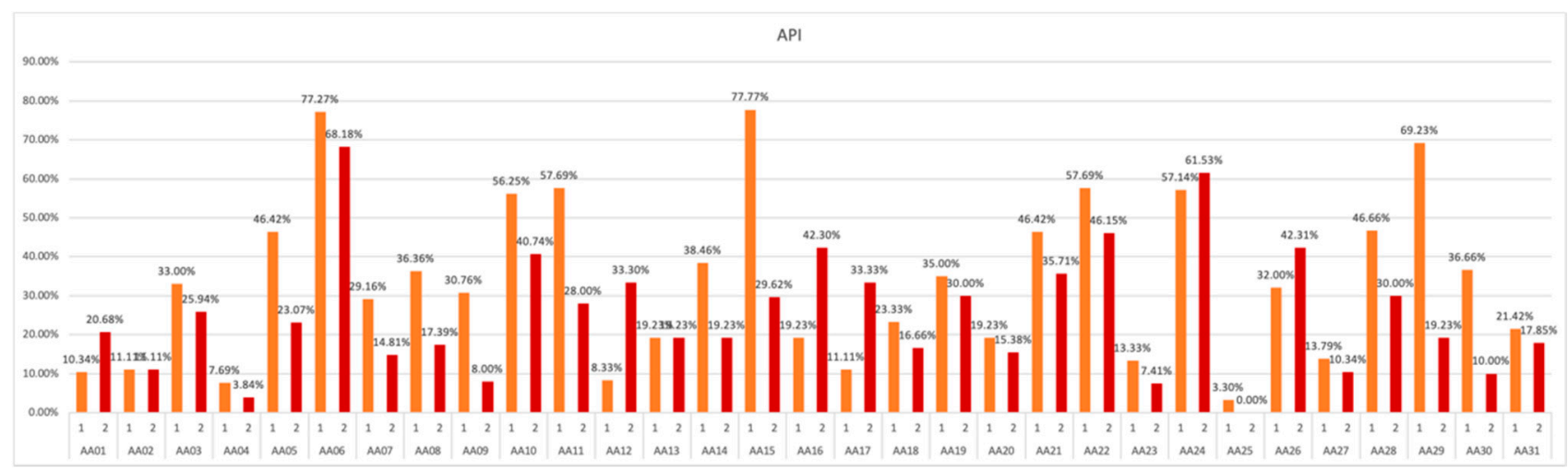

Figure 6. API values obtained in subsequent measurements over the course of study.

Due to the clinical significance and application of the indicator as well as the wide spectrum of results obtained from the patients, the interpretation of the results should be carried out with the division of patients into categories and their potential change should be traced.

The data should also be analyzed in terms of the subjects' assigned initial and final API category, as achieved scores can be in the borderline category and the participant's significant improvement/deterioration in hygiene can be omitted (Figure 7).

\section{API category change over the course of study}

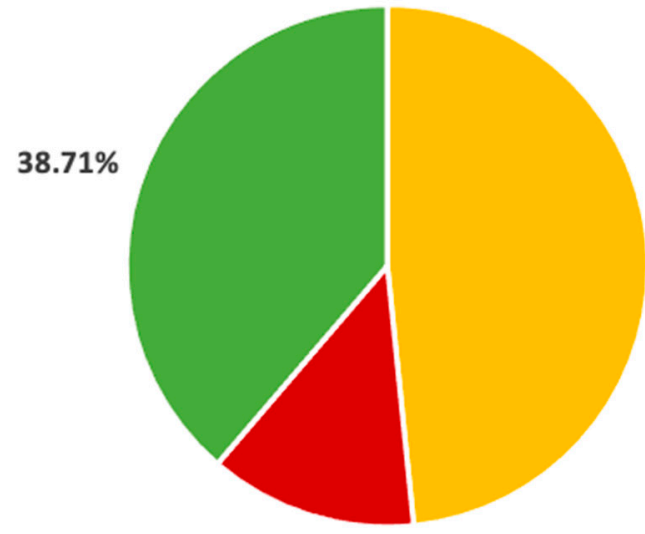

$12.90 \%$
$48.39 \%$

no category change
- category increse
(hygiene deterioration)
category decrese
(hygiene improvement)

Figure 7. Participants' potential API category change over the course of study.

Tracing the change in the API category over the course of the study, we can observe notable deterioration (category increase) occurring only in $12.90 \%$ of participants and significant hygiene improvement (category decrease) in $38.71 \%$ of AAs.

\subsection{Simplified Oral Hygiene Index}

The sOHI indicator assesses the amount of plaque and calculus on the tooth surface. The measurement of the two components of plaque and calculus was completed on six teeth on different surfaces, including the facial side of three maxillary teeth, the lingual side of the two posterior mandibular teeth and the labial side of one anterior mandibular tooth. The indicator determines the ratio of the surfaces covered with dental plaque and calculus of the selected teeth to all selected surfaces. The cumulative plaque and calculus score allows one to assess the oral hygiene by classifying the results into three groups: 
1. $\quad 0-2 \rightarrow$ good hygiene;

2. $\quad 2.1-4 \rightarrow$ sufficient hygiene;

3. $4.1-6 \rightarrow$ poor hygiene.

The presented data demonstrate that, in $25.81 \%$ of the participants, the hygiene was kept at a constant good level, and $54.84 \%$ improved over the duration of experiment, where slight worsening of oral hygiene was observed in $19.35 \%$ of analog astronauts (Figure 8 ).

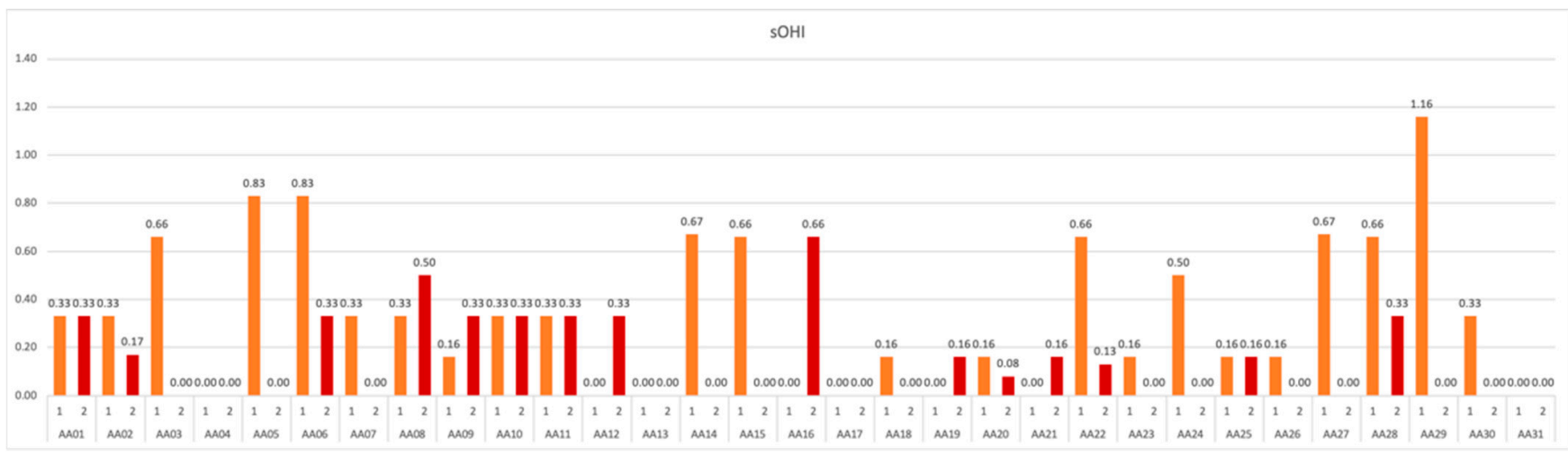

Figure 8. sOHI values obtained in subsequent measurements over the course of study.

\subsection{Plaque Index by Silness and Loe}

The PI (by Silness and Loe) determines the thickness of the plaque along the edge of the teeth' gingiva in relation to all cervical area present. The measurement of the state of oral hygiene by the Silness-Löe plaque index is based on recording both soft debris and mineralized deposits on the selected teeth. Each of the four surfaces of the teeth (buccal, lingual, mesial and distal) is given a score from $0-3$. The scores from the four areas of the tooth are added and divided by four in order to give the plaque index for the tooth; the procedure is repeated for all selected teeth, and the cumulative plaque index of all teeth is divided into the number of examined teeth. This indicator allows one to assess the hygiene in the cervical area by classifying subjects into three groups:

1. $\quad 0-2 \rightarrow$ good hygiene;

2. $\quad 2.1-4 \rightarrow$ sufficient hygiene;

3. $\quad 4.1-6 \rightarrow$ poor hygiene.

The data show that in $16.13 \%$ of the subjects the hygiene was maintained at a constant good level throughout the experiment, and in $67.74 \%$ it improved slightly. A small deterioration of the PI score was observed only in 5 out of 31 participants (Figure 9).

PI

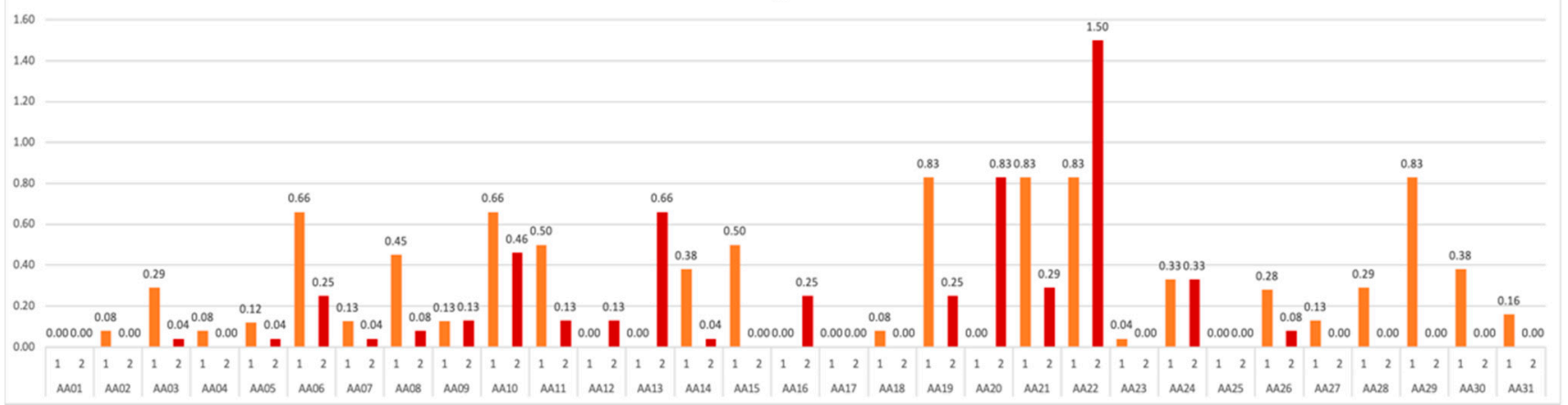

Figure 9. PI values obtained in subsequent measurements over the course of study. 


\subsection{Gingival Bleeding Index by Ainamo and Bay (1975)}

The GBI-Gingival Bleeding Index by Ainamo and Bay (1975) determines the percentage of the gingival sulcus with bleeding during probing in relation to all examined gingival sulcus area present. Measurement is performed through gentle probing of the orifice of the gingival crevice. If bleeding occurs within $10 \mathrm{~s}$ a positive finding is recorded, and if no bleeding occurs, a negative result is noted.

This indicator enables the capture of gingival inflammation and the early stages of periodontal disease, classifying the results obtained from the examined person into four categories:

1. $\quad 0-10 \% \rightarrow$ clinically healthy periodontium;

2. $\quad 11-29 \% \rightarrow$ localized, mild gingival inflammation;

3. $\quad 30-49 \% \rightarrow$ generalized moderate gingival inflammation;

4. $50-100 \% \rightarrow$ severe and generalized gingival inflammation.

If, during the analog space mission, a decreasing number of gingival bleeding sides is observed, it represents the reduction of gingival inflammation and the improvement of the periodontium status. This demonstrates the correctness of the oral hygiene techniques. The collected data should be analyzed in terms of a possible increase or decrease, but also considering the assigned GBI category, which is a significant improvement/deterioration of the periodontal health, i.e., when the subject is assigned a lower/higher GBI category, respectively (Figure 10).

GBI

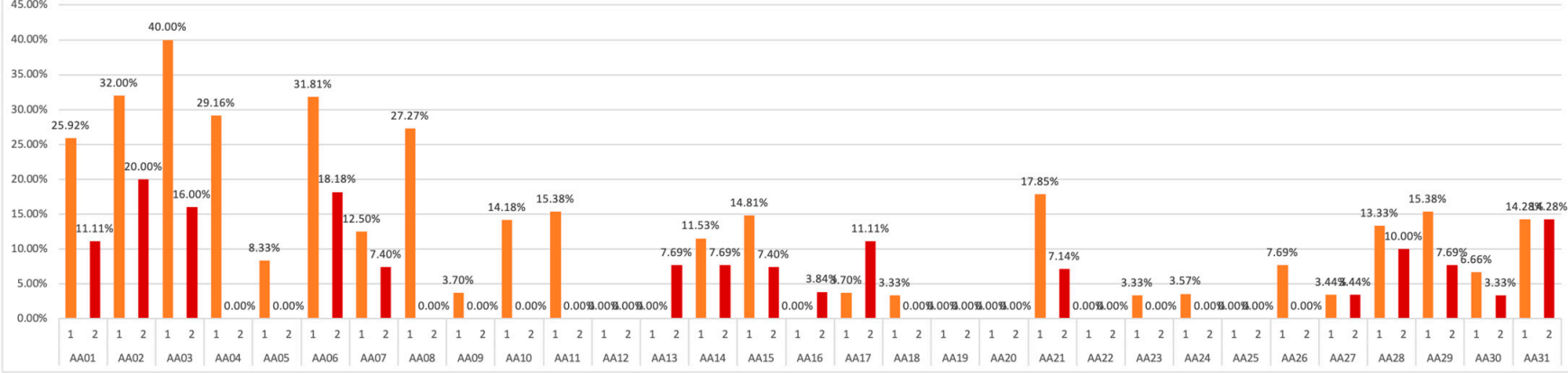

Figure 10. GBI values obtained in subsequent measurements over the course of study.

The collected data demonstrate that, in $67.74 \%$ of participants of the study, there was a decrease in the number of bleeding sites, confirming an improvement of periodontal health. Maintenance of a constant good level throughout the experiment can be observed in $22.58 \%$ of the subjects and a small deterioration of the GBI score was noted only in three (out of 31) participants during six analog missions.

Due to the clinical significance and application of the indicator as well as the wide spectrum of results obtained from the patients, the interpretation of the results should be carried out with the division of patients into categories, and their potential change should be traced.

The data should be analyzed in terms of the subjects' assigned initial and final GBI category, as achieved scores can be on the category borderline and participant significant hygiene improvement/deterioration can be omitted (Figure 11). 


\section{GBI category change over the course of study}

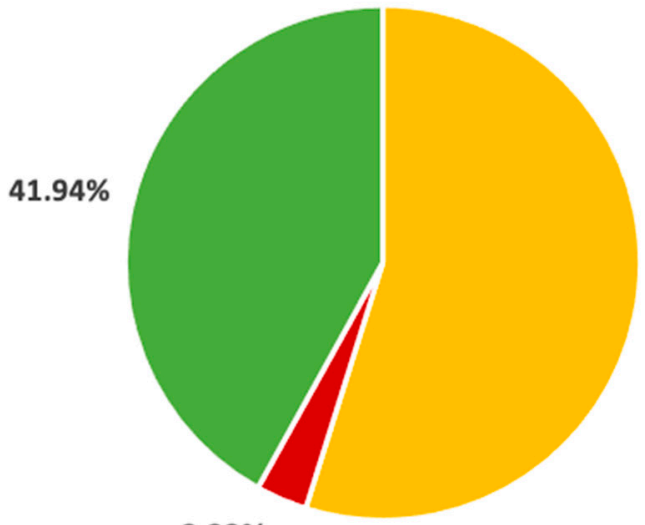

$54.84 \%$

= no category change

$3.23 \%$

(hygiene deterioration)

- category decrese

(hygiene improvement)

Figure 11. Participants' potential GBI category change over the course of study.

It is also worth noting the clinical significance of the indicator and the potentially significant improvement/deterioration of the gingival status-assigning the lower/higher GBI category, respectively-over the course of the experiment. Tracing the GBI category change over the course of study, we can observe that notable deterioration (category increase) occurred only in 3.23\% of participants and significant hygiene improvement (category decrease) in $41.94 \%$ of AAs.

\subsection{Summary and Analysis of Collected Data}

Individual AA scores were comprehensively analyzed in relation to all collected data and overall average results for initial and final measurements were calculated to observe the average change of particular indicators throughout the experiment (Figure 12).

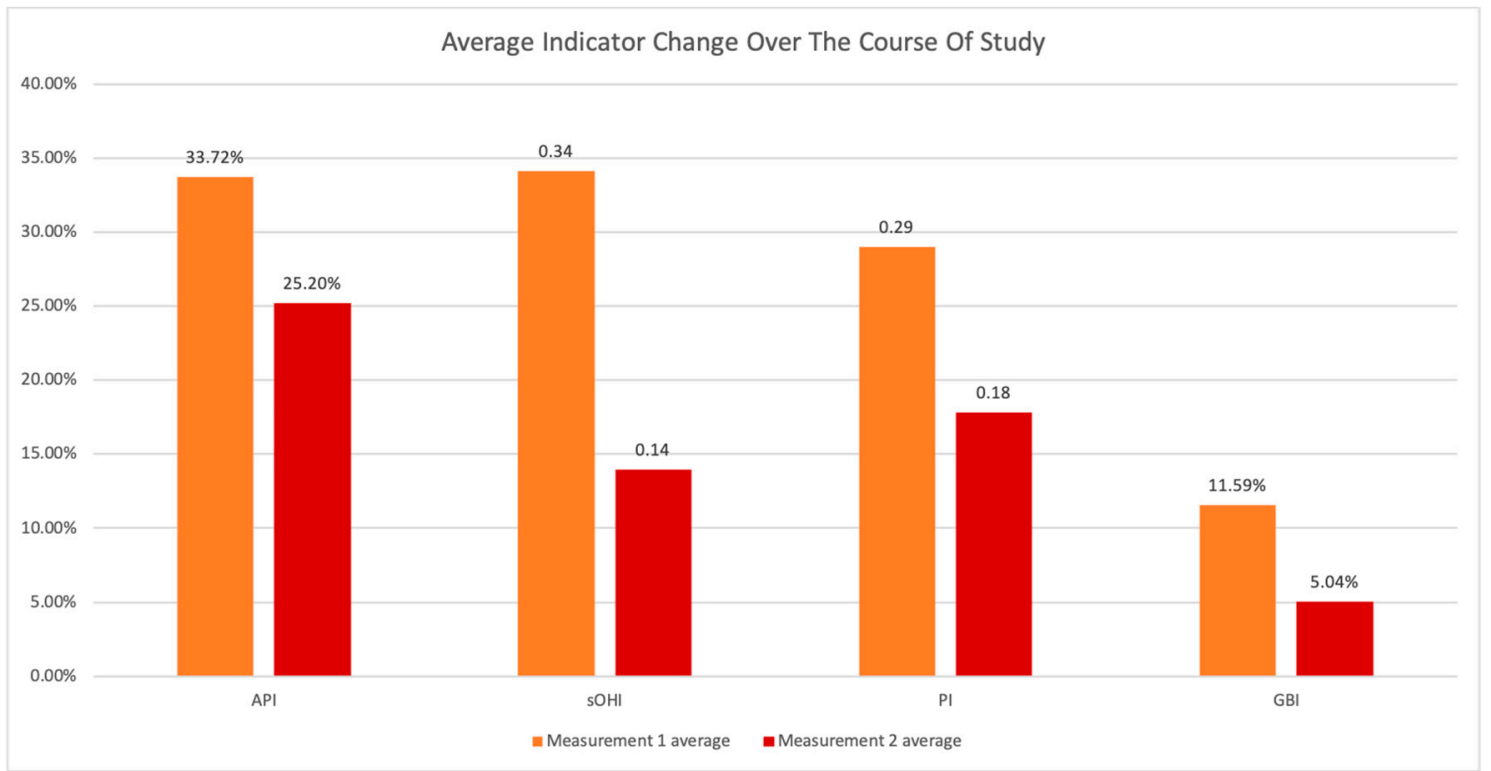

Figure 12. Average indicator change over the course of study. 
All data were statistically analyzed in STATISCA 13.3 software and considered statistically significant for $p$-value equal to or less than 0.05 . This value proves the correctness of the observed dependencies (Table 2).

Table 2. Statistical significance of individual examined indicators.

\begin{tabular}{cc}
\hline Oral Hygiene/Gingival Inflammation Indicator & $\boldsymbol{p}$-Value \\
\hline Approximal Plaque Index (API) & 0.0782 \\
\hline Simplified Oral Hygiene Index (sOHI) & 0.0068 \\
\hline Plaque Index by Silness and Loe (PI) & 0.0345 \\
\hline Gingival Bleeding Index by Ainamo and Bay (GBI) & 0.0149 \\
\hline
\end{tabular}

Measurements of sOHI, PI and GBI indices demonstrated statistically significant differences (sOHI $p$-value: 0.0068; PI $p$-value: 0.0345; GBI $p$-value: 0.0149 ), establishing that implemented a oral hygiene regimen with the use of appropriate products and techniques can decrease dental plaque accumulation and gingival inflammation.

The API measurements exhibited a strong downward trend (API $p$-value: 0.0782), which could indicate a decrease in the amount of interdental plaque in the studied ana$\log$ astronauts, as a result of the applied oral hygiene procedures based on appropriate instruments and techniques.

\section{Discussion}

Research demonstrates that being in isolation causes stress, malaise and depression and may disrupt the daily routine [21]. Maintaining it for a longer period may lead to serious health disorders [22]. These dependencies may lead to loneliness, social isolation [23] and reduced quality of life, which is, unfortunately, often observed more and more among the elderly, who are deprived of contact with other people [24]. Another example of a group struggling with such problems is people in quarantine, in isolation or in extreme space conditions, such as astronauts. In addition to the negative effects on mental health, studies show serious physical consequences of long-term social isolation [24].

In terms of dentistry, isolation can affect the oral hygiene of patients, which can lead to an increased risk of tooth decay and gingivitis. The research clearly demonstrates that the improvement of dental hygiene has a direct positive effect on the periodontal health and contributes to the reduction of the risk of caries [25]. Consumption of starchy staple foods and fresh fruit is associated with low levels of dental caries [26], but because of products' sophisticated freeze-drying process, of drying after vacuum freezing [9], the food provided to the astronauts does not possess the same qualities. Lyophilized food has a stickier consistency and tends to adhere better to smooth surfaces. As a result, astronauts are much more prone to increased caries and gingival inflammation risks. A prolonged lyophilized diet also has a negative effect on the composition or amount of saliva, due to the dehydration of the organism, which can even lead to xerostomia [18]. The consequences of dry mouth disease may be dental caries, dysgeusia, soreness of the oral mucosa and oral candidiasis [27]. If oral hygiene is neglected in the environment of increased mouth dryness, such as during isolation or daily routine disturbance, it may have a negative effect and progress rapidly [27].

People in extreme conditions, such as astronauts, are often subjected to very high stress and are isolated from others. This makes them a good research group for the relationship between isolation, dental hygiene and a freeze-dried diet. In this study, it was observed that even in unfavorable dietary and stressful isolation conditions, the mentioned trends were confirmed, and that they do not determine the persons' oral hygiene status as well as periodontal health. In conditions of appropriate oral hygiene technique and establishing oral hygiene daily routine, improvement in oral health and dental hygiene can be observed within only 14 days. The lack of statistical significance for all indicators is probably due to the wide spectrum of API scores within a small tested group, whilst the literature suggests 
that this hygiene indicator used in larger studies is very reliable and often demonstrates hygiene improvement or deterioration [28].

The observations made by the research team are directly relevant to everyday life, especially for people staying in quarantine or enduring prolonged isolation conditions. Specially designed oral hygiene regimen could be also implemented in the preparation process for people planning endeavors, such as space travel, mountain climbing or survival trips. Especially for astronauts, the preparation process often takes a very long time, during which proper hygiene habits could be developed and sustained throughout the duration of the mission, which could minimize the risk of caries or gingivitis occurrence.

It has been reported that some organic and environmentally friendly solutions, such as green tea, have been tested and demonstrated a promising beneficial impact on periodontal tissues [29], but due to the strict isolation and dietary regulations of this study (drinking green tea was not allowed for participants), they were not taken under consideration.

Other studies suggest the use of novel organic solutions, such as ozonated olive oil, as mouthwash for patients with periodontal problems [30], but most likely in non-severe cases, well-designed hygiene instructions and adherence to strict hygiene regimen can bring positive effect without the use of any mouthwash, to which analog astronauts did not have access to throughout the course of the study. In case of the presence of participants with more severe periodontal problems, this novel solution can be considered in future studies.

Codispoti et al. suggest that solutions to aid patients with more severe periodontal problems can be technologies based on exosomal activity (NANOBIOME) [31,32], which could help, especially in remote conditions or prolonged isolation. People returning from an environment where sometimes oral hygiene is not a top priority, could use such novel approaches to improve their poor oral state after neglecting their hygiene. Despite this unique perspective, the research team concluded from the gathered data (where severe cases of periodontal issues were not present) that adherence to instructions and strict hygiene regimen can be sufficient in most cases.

Due to the fact that analog space research is not yet mainstream and that this field still needs a lot of expansion, most studies conducted during analog missions are innovative and pioneering. In addition, because of the low number of facilities and their availability to researchers from all science spectra, some research has never been conducted before in the aforementioned extreme conditions and on this particular test group. The constant development of research and its interdisciplinary nature as well as the uniqueness of the studied conditions makes this difficult to discuss with other researchers, due to the limited number of publications about the subject matter.

\section{Limitations}

The main limitations of the study were the small and ethnically heterogenic group of study participants, who varied in age (21-60 years of age), dietary and hygienic habits as well as oral cavity status. The only exclusion factors for study participation were: lack of good state of overall health and presence of serious gastric problems, which could restrict the analog astronauts from consuming the freeze-dried diet.

\section{Conclusions}

(1) The study demonstrates that a freeze-dried diet in isolation conditions exclusively appears to not have a negative effect on oral hygiene and gingival status.

(2) The most probable cause of plaque accumulation and gingival inflammation, intensified by sticky consistency of freeze-dried food, seems to be the neglect of oral hygiene habits.

(3) Individual oral hygiene training (iOHT) ensures correct technique performance and maintaining regular hygiene habits during isolation. iOHT should be incorporated into a preparation protocol for analog space missions and other extreme isolation endeavors.

(4) Research should be continued at the LunAres Research Station to increase the sample size. 
Author Contributions: Conceptualization, B.J.G., K.K. (Karina Kijak), K.K. (Kamil Kosko) and M.M.; methodology, B.J.G., H.A.G. and D.L.-K.; validation, K.J., H.A.G., W.P. and D.L.-K.; formal analysis, K.J. and W.P.; investigation, B.J.G., K.K. (Karina Kijak) and K.K. (Kamil Kosko); resources, H.A.G. and D.L.-K.; writing—original draft preparation, B.J.G. and K.K. (Karina Kijak); writing-review and editing, H.A.G. and D.L.-K.; supervision, H.A.G., H.B.B.-V., W.P. and D.L.-K.; project administration, B.J.G., K.K. (Kamil Kosko), L.O. and D.L.-K.; funding acquisition, D.L.-K. All authors have read and agreed to the published version of the manuscript.

Funding: This research received no external funding.

Institutional Review Board Statement: The study was conducted according to the guidelines of the Declaration of Helsinki, and approved by the Ethics Committee of the Pomeranian Medical University in Szczecin (protocol code KB-0012/105/18 and date of approval: 22 October 2018).

Informed Consent Statement: Informed consent was obtained from all subjects involved in the study.

Data Availability Statement: Not applicable.

Conflicts of Interest: The authors declare no conflict of interest.

\section{Appendix A}

Dietary information of the analog space mission.

Each of the participants could choose their meals (breakfast, second breakfast, lunch, dessert, and dinner) from the following list and during the analog mission had to adhere to predetermined choices and meal preparation instructions.

All freeze-dried products were produced by the company, LYOFOOD Sp. z o. o. (Poland).

\begin{tabular}{|c|c|c|c|c|}
\hline Type of Meal & Dish Name & Net Weight (g) & $\begin{array}{l}\text { Amount of Added } \\
\text { Water (mL) }\end{array}$ & Ingredients \\
\hline \multirow{4}{*}{ Breakfast } & $\begin{array}{l}\text { Organic millet porridge } \\
\text { with raspberries and } \\
\text { aronian powder }\end{array}$ & 100 & 200 & $\begin{array}{c}\text { organic millet } 72 \% \text {, organic coconut } \\
\text { milk } 19 \% \text {, organic agave syrup } 6 \% \text {, } \\
\text { organic raspberry crumble } 2 \% \text {, organic } \\
\text { aronia powder } 1 \%\end{array}$ \\
\hline & $\begin{array}{l}\text { Organic poridge with } \\
\text { apple, cranberries, } \\
\text { cinamon and chia seeds }\end{array}$ & 70 & 140 & $\begin{array}{l}\text { bio gluten-free oats } 54 \% \text {, bio coconut } \\
\text { milk } 37 \% \text {, bio agave syrup, bio apple } \\
\text { cubes } 2 \% \text {, bio chia seeds, bio cranberry } \\
\text { slices, bio cinnamon powder }\end{array}$ \\
\hline & $\begin{array}{l}\text { Coconut porridge with } \\
\text { blueberries, figs and } \\
\text { chia seeds }\end{array}$ & 100 & 200 & $\begin{array}{c}\text { gluten-free oats } 53 \% \text {, organic coconut } \\
\text { milk } 37 \% \text {, figs slices } 4 \% \text {, organic agave } \\
\text { syrup } 4 \% \text {, organic chia seeds, } \\
\text { blueberries whole }\end{array}$ \\
\hline & Mexican scrambled eggs & 75 & 195 & $\begin{array}{c}\text { egg mix (eggs, citric acid) } 39 \% \text {, red } \\
\text { bell pepper } 14 \% \text {, onion } 14 \% \text {, sweet } \\
\text { corn, red bean } 12 \% \text {, cheese (sheep's } \\
\text { milk, salt, rennet), olive oil, coriander } \\
\text { leaves, chili, garlic, salt }\end{array}$ \\
\hline \multirow{7}{*}{ 2nd breakfast } & Fruity dream & 30 & 0 & $\begin{array}{c}\text { freeze-dried strawberries } 33 \% \text {, apple } \\
33 \% \text {, sour cherries } 33 \%\end{array}$ \\
\hline & Wild berry mix & 30 & 0 & $\begin{array}{c}\text { freeze-dried raspberries 33\%, } \\
\text { blueberries 33\%, blackberries 33\% }\end{array}$ \\
\hline & Exotic pleasure & 30 & 0 & $\begin{array}{c}\text { freeze-dried tangerines } 25 \% \text {, kiwi } 25 \% \text {, } \\
\text { banana } 25 \% \text {, pineapple } 25 \%\end{array}$ \\
\hline & Strawberries & 20 & 0 & freeze-dried strawberries $100 \%$ \\
\hline & Banana & 30 & 0 & freeze-dried banana $100 \%$ \\
\hline & Apple & 30 & 0 & freeze-dried apple $100 \%$ \\
\hline & Cherry & 30 & 0 & freeze-dried sour cherry $100 \%$ \\
\hline
\end{tabular}




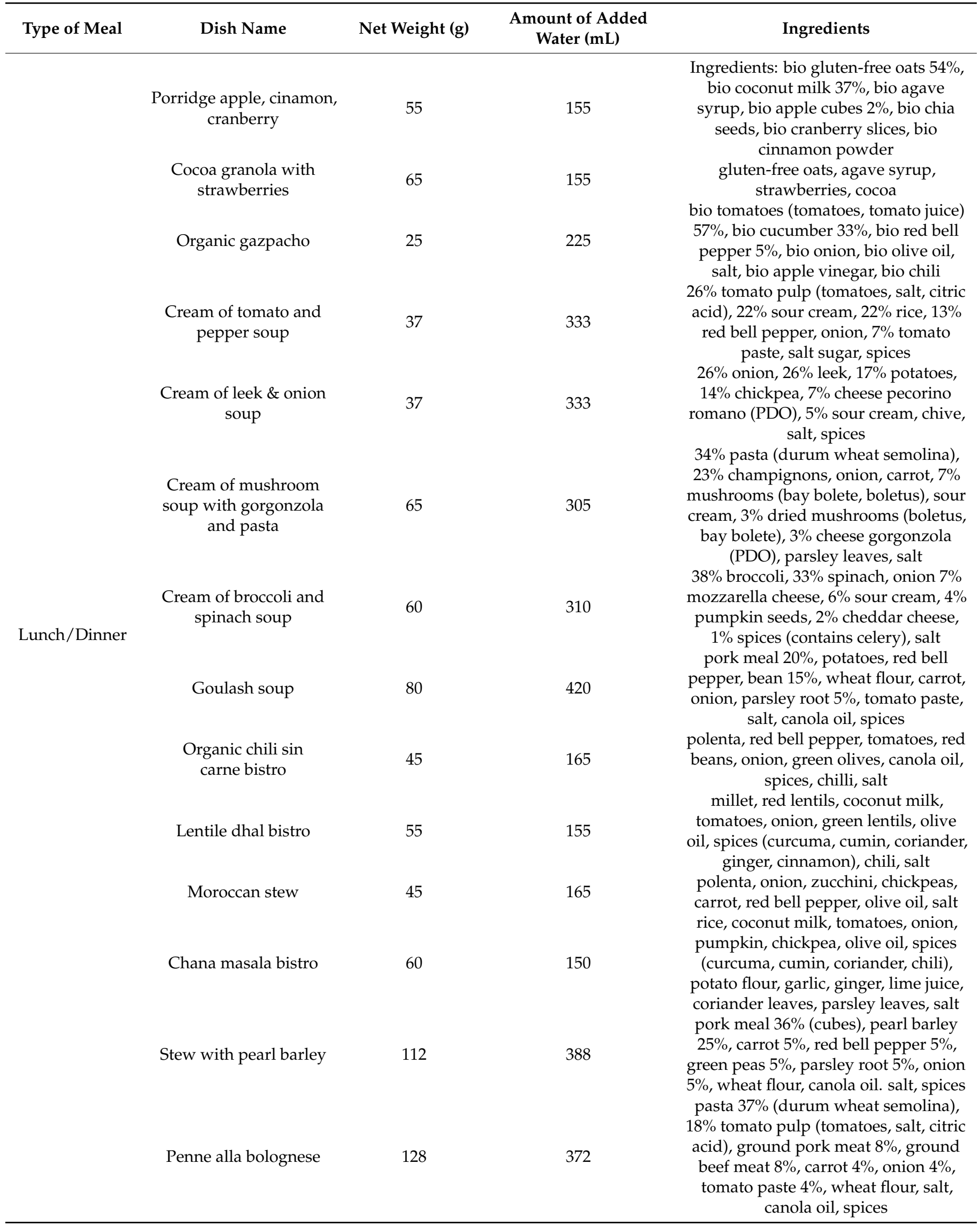




$\begin{array}{llcc}\text { Type of Meal Dish Name } & \text { Net Weight (g) } & \begin{array}{c}\text { Amount of Added } \\ \text { Water }(\mathrm{mL})\end{array} & \text { Ingredients }\end{array}$

Barley lentils risotto with avocado mousse

Pork loin in green pepper

Pork loin in green pepper

Pork loin in dill

Pork loin in dill

Organic chili sin carne

Mexican dish

Mexican dish

Bigos

Farfalle with gorgonzola and spinach sauce

Farfalle with gorgonzola and spinach sauce

Five spice chicken red bell pepper $41 \%$, green lentils $14 \%$, pearl barley $12 \%$, leek, avocado $5 \%$, pumpkin seeds, lemon juice, parsley, olive oil, salt, spices, herbs

pork loin 35\% (cubes), potatoes $26 \%$, green beans, onion, wheat flour, green peppercorn $2 \%$, canola oil, salt, spices pork loin $35 \%$ (cubes), potatoes $26 \%$, green beans, onion, wheat flour, green peppercorn $2 \%$, canola oil, salt, spices pork loin $35 \%$ (cubes), potatoes $26 \%$, carrot, parsley root, leek, onion, broccoli, cauliflower, wheat flour, canola oil, salt, spices, dill $0.03 \%$ pork loin $35 \%$ (cubes), potatoes $26 \%$, carrot, parsley root, leek, onion, broccoli, cauliflower, wheat flour, canola oil, salt, spices, dill $0.03 \%$ bio polenta $28 \%$, bio red bell pepper $19 \%$, bio tomatoes (tomatoes, tomato juice), bio red bean $15 \%$, bio onion, bio green olives, bio canola oil, bio spices, salt, bio chili $0.04 \%$

chicken breast fillet $35 \%$ (cubes), rice $26 \%$, red bean $11 \%$, red bell pepper $4 \%$, sweet corn $4 \%$, onion, wheat flour, tomato paste, canola oil, salt, spices chicken breast fillet $35 \%$ (cubes), rice $26 \%$, red bean $11 \%$, red bell pepper $4 \%$, sweet corn $4 \%$, onion, wheat flour, tomato paste, canola oil, salt, spices ssauerkraut 59\% (sauerkraut, carrot, salt), pork meat $17 \%$ (cubes), $6 \%$ chicken fillet (cubes), champignon mushrooms, tomato paste, canola oil, dried boletus mushrooms, smoked plums, spices

spinach $44 \%$, pasta $27 \%$ (durum wheat semolina), onion, sour cream, gorgonzola $5 \%$, almonds $2 \%$, salt garlic, butter

spinach $44 \%$, pasta $27 \%$ (durum wheat semolina), onion, sour cream, gorgonzola $5 \%$, almonds $2 \%$, salt garlic, butter

rice $33 \%$, chicken breast fillet $28 \%$ (cubes), vegetables in varying proportions $23 \%$, (mung bean sprouts, red bell pepper, red onion, jelly ear mushrooms, bamboo shoots, carrot, leek, onion), potato flour, salt, soy sauce (soy beans, salt, wheat flour), spices 


$\begin{array}{llcc}\text { Type of Meal } \quad \text { Dish Name } & \text { Net Weight }(\mathrm{g}) & \begin{array}{c}\text { Amount of Added } \\ \text { Water }(\mathrm{mL})\end{array} & \text { Ingredients }\end{array}$

Five spice chicken

100

400

Chicken tikka masala

128

372

Strogonof

113

Nettle curry

Beef strogonof

152

Organic lentil dal with millet

Catalonian cream

Apple crumble

Snack/Dessert

Chocolate pudding

Red smoothie

Green smoothie

Red vitamin drink rice $33 \%$, chicken breast fillet $28 \%$ (cubes), vegetables in varying proportions $23 \%$, (mung bean sprouts, red bell pepper, red onion, jelly ear mushrooms, bamboo shoots, carrot, leek, onion), potato flour, salt, soy sauce (soy beans, salt, wheat flour), spices

rice $26 \%$, tomato pulp $23 \%$ (tomatoes, salt, citric acid), chicken breast fillet

(strips) $21 \%$, greek yoghurt $20 \%$, coconut milk $4 \%$, almonds $2 \%$, canola oil, salt, spices (contains mustard), sugar noodles $41 \%$ (durum wheat semolina), beef $33 \%$ (strips), champignons $7 \%$, onion $4 \%$, red bell pepper, wheat flour, pickled cucumber, mustard (mustard seeds, vinegar, salt, suger, turmeric), tomato paste, canola oil, salt, paprika, pepper, spices

rice $30 \%$, coconut milk $25 \%$, sugar peas, carrot, pumpkin, broccoli, zucchini, coriander leaves, nettle $1 \%$, lime juice $1 \%$, lemon grass, salt, green chili $0.4 \%$, spices noodles $41 \%$ (durum wheat semolina), beef $33 \%$ (strips), champignons $7 \%$, onion $4 \%$, red bell pepper, wheat flour, pickled cucumber, mustard (mustard seeds, vinegar, salt, suger, turmeric), tomato paste, canola oil, salt, paprika, pepper, spices

bio millet $37 \%$, bio tomatoes (tomatoes, tomato juice) $14 \%$, bio red lentils $12 \%$, bio coconut milk $12 \%$, bio onion, bio green lentils $5 \%$, bio olive oil, salt, spices, cumin, curcuma, ginger

$77 \%$ milk origin: Poland, $10 \%$ egg yolks, $6 \%$ sugar, potato flour, orange peel, cinnamon

wheat flour 39\%, butter $29 \%$, sugar, apple $13 \%$, cinnamon

milk $62 \%$, chocolate $18 \%$ (cocoa paste, cane sugar, cocoa butter), sugar, egg mix 6\%(eggs, citric acid), potato flour strawberries $29 \%$, banana $29 \%$, peach $21 \%$, blackcurrant $14 \%$, cranberries $7 \%$ apple $35 \%$, kiwi $35 \%$, pineapple $21 \%$,

spinach $4 \%$, nettle $4 \%$, ginger strawberry $53 \%$, blackcurrant $35 \%$, beetroot $12 \%$ 


\section{References}

1. McMenamin, J.; Allen, N.J.; Battler, M. Team Processes and Outcomes during the AMADEE-18 Mars Analog Mission. Astrobiology 2020, 20, 1287-1294. [CrossRef] [PubMed]

2. Lalla, E.A.; Cote, K.; Hickson, D.; Garnitschnig, S.; Konstantinidis, M.; Such, P.; Czakler, C.; Schroder, C.; Frigeri, A.; Ercoli, M.; et al. Laboratory Analysis of Returned Samples from the AMADEE-18 Mars Analog Mission. Astrobiology 2020, 20, 1303-1320. [CrossRef] [PubMed]

3. Bortolaia, C.; Sbordone, L. I biofilm del cavo orale. Formazione, sviluppo e implicazioni nell'insorgenza delle malattie correlate all'accumulo di placca batterica [Biofilms of the oral cavity. Formation, development and involvement in the onset of diseases related to bacterial plaque increase]. Minerva Stomatol. 2002, 51, 187-192. [PubMed]

4. $\quad$ Bressan, E.; Ferroni, L.; Gardin, C.; Bellin, G.; Sbricoli, L.; Sivolella, S.; Brunello, G.; Schwartz-Arad, D.; Mijiritsky, E.; Penarrocha, M.; et al. Metal Nanoparticles Released from Dental Implant Surfaces: Potential Contribution to Chronic Inflammation and Peri-Implant Bone Loss. Materials 2019, 12, 2036. [CrossRef]

5. Pansare, S.K.; Patel, S.M. Lyophilization Process Design and Development: A Single-Step Drying Approach. J. Pharm. Sci. 2019, 108, 1423-1433. [CrossRef]

6. Silva-Espinoza, M.A.; Ayed, C.; Foster, T.; Camacho, M.D.M.; Martínez-Navarrete, N. The Impact of Freeze-Drying Conditions on the Physico-Chemical Properties and Bioactive Compounds of a Freeze-Dried Orange Puree. Foods 2019, 30, 32. [CrossRef]

7. Perchonok, M.; Bourland, C. NASA food systems: Past, present, and future. Nutrition 2002, 18, 913-920. [CrossRef]

8. Cooper, M.; Douglas, G.; Perchonok, M. Developing the NASA Food System for Long- Duration Missions. J. Food Sci. 2011, 76, 40-48. [CrossRef]

9. Sun, G.S.; Tou, J.C.; Yu, D.; Girten, B.E.; Cohen, J. The past, present, and future of National Aeronautics and Space Administration spaceflight diet in support of microgravity rodent experiments. Nutrition 2014, 30, 125-130. [CrossRef]

10. Marques, L.G.; Silveira, A.M.; Freire, J.T. Freeze-Drying Characteristics of Tropical Fruits. Dry. Technol. 2006, 24, 457-463. [CrossRef]

11. Araya-Farias, M.; Makhlouf, J.; Ratti, C. Drying of Seabuckthorn (Hippophae rhamnoides L.) Berry: Impact of Dehydration Methods on Kinetics and Quality. Dry. Technol. 2011, 29, 351-359. [CrossRef]

12. Bhatta, S.; Stevanovic Janezic, T.; Ratti, C. Freeze-Drying of Plant-Based Foods. Foods 2020, 9, 87. [CrossRef] [PubMed]

13. Sablani, S.S.; Andrews, P.K.; Davies, N.M.; Walters, T.; Saez, H.; Bastarrachea, L. Effects of Air and Freeze Drying on Phytochemical Content of Conventional and Organic Berries. Dry. Technol. 2011, 29, 205-216. [CrossRef]

14. Asami, D.K.; Hong, Y.J.; Barrett, D.M.; Mitchell, A.E. Comparison of the Total Phenolic and Ascorbic Acid Content of Freeze-Dried and Air-Dried Marionberry, Strawberry, and Corn Grown Using Conventional, Organic, and Sustainable Agricultural Practices. J. Agric. Food Chem. 2003, 51, 1237-1241. [CrossRef] [PubMed]

15. Reyes, A.; Evseev, A.; Mahn, A.; Bubnovich, V.; Bustos, R.; Scheuermann, E. Effect of operating conditions in freeze-drying on the nutritional properties of blueberries. Int. J. Food Sci. Nutr. 2011, 62, 303-306. [CrossRef] [PubMed]

16. Dorsky, R. Nutrition and oral health. Gen. Dent. 2001, 49, 576-582. [PubMed]

17. Lingström, P.; Moynihan, P. Nutrition, Saliva and Oral Health. Nutrition 2003, 19, 567-569. [CrossRef]

18. Kubala, E.; Strzelecka, P.; Grzegocka, M.; Lietz- Kijak, D.; Gronwald, H.; Skomro, P.; Kijak, E. A review of selected studies that determine the physical and chemical properties of saliva in the field of dental treatment. Biomed Res. Int. 2018, 2018, 6572381. [CrossRef]

19. Sadler, M.J.; Gibson, S.; Whelan, K.; Ha, M.-A.; Lovegrove, J.; Higgs, J. Dried fruit and public health-what does the evidence tell us? Int. J. Food Sci. 2019, 70, 675-687. [CrossRef]

20. Sadler, M.J. Dried fruit and dental health. Int. J. Food Sci. 2016, 67, 944-959. [CrossRef]

21. Cotterell, N.; Buffel, T.; Phillipson, C. Preventing social isolation in older people. Maturitas 2018, 113, 80-84. [CrossRef]

22. Koyama, S.; Saito, M.; Cable, N.; Ikeda, T.; Tsuji, T.; Noguchi, T.; Abbas, H.; Miyashiro, I.; Osaka, K.; Kondo, K.; et al. Examining the associations between oral health and social isolation: A cross-national comparative study between Japan and England. Soc. Sci. Med. 2021, 277, 113895. [CrossRef] [PubMed]

23. Winterton, A.; Rødevand, L.; Westlye, L.T.; Steen, N.E.; Andreassen, O.A.; Quintana, D.S. Associations of loneliness and social isolation with cardiovascular and metabolic health: A systematic review and meta-analysis protocol. Syst. Rev. 2020, 9, 102. [CrossRef]

24. Galea, S.; Merchant, R.M.; Lurie, N. The mental health consequences of COVID-19 and physical distancing: The need for prevention and early intervention. JAMA Intern. Med. 2020, 180, 817-818. [CrossRef]

25. Löe, H. Oral hygiene in the prevention of caries and periodontal disease. Int. Dent. J. 2000, 50, 129-139. [CrossRef]

26. Moynihan, P.; Petersen, P.E. Diet, nutrition and the prevention of dental diseases. Public Health Nutr. 2004, 7, 201-226. [CrossRef]

27. Thomson, W.M.; Chalmers, J.M.; Spencer, A.J.; Slade, G.D.; Carter, K.D. A longitudinal study of medication exposure and xerostomia among older people. Gerodontology 2006, 23, 205-213. [CrossRef]

28. Kalandyk-Konstanty, A.; Konstanty-Kalandyk, J.; Zarzecka, J.; Sadowski, J.; Drwila, R.; Bartus, K.; Darocha, T.; Piatek, J.; Kapelak, B. The effect of proper oral hygiene habits on oral cavity health. Dent. Med. Probl. 2017, 54, 167-171. [CrossRef]

29. Mazur, M.; Ndokaj, A.; Jedlinski, M.; Ardan, R.; Bietolini, S.; Ottolenghi, L. Impact of Green Tea (Camellia Sinensis) on periodontitis and caries. Systematic review and meta-analysis. Jpn. Dent. Sci. Rev. 2021, 57, 1-11. [CrossRef] 
30. Nardi, G.M.; Cesarano, F.; Papa, G.; Chiavistelli, L.; Ardan, R.; Jedlinski, M.; Mazur, M.; Grassi, R.; Grassi, F.R. Evaluation of Salivary Matrix Metalloproteinase (MMP-8) in Periodontal Patients Undergoing Non-Surgical Periodontal Therapy and Mouthwash Based on Ozonated Olive Oil: A Randomized Clinical Trial. Int. J. Environ. Res. Public Health 2020, $17,6619$. [CrossRef]

31. Codispoti, B.; Marrelli, M.; Paduano, F.; Tatullo, M. NANOmetric BIO-Banked MSC-Derived Exosome (NANOBIOME) as a Novel Approach to Regenerative Medicine. J. Clin. Med. 2018, 7, 357. [CrossRef] [PubMed]

32. Tatullo, M.; Marrelli, B.; Zullo, M.J.; Codispoti, B.; Paduano, F.; Benincasa, C.; Fortunato, F.; Scacco, S.; Zavan, B.; Cocco, T. Exosomes from Human Periapical Cyst-MSCs: Theranostic Application in Parkinson's Disease. Int. J. Med. Sci. 2020, 17, 657-666. [CrossRef] [PubMed] 